\title{
Development of copper alloy by microwave hybrid heating technique and its characterization
}

\author{
Shashank L. Marahadige ${ }^{*}$, Srinath M. Sridharmurthy ${ }^{2}$, Amarendra H. Jayraj ${ }^{3}$, Ulavathi S. Mahabaleshwar ${ }^{4}$, Giulio Lorenzini $^{5}$, \\ Enrico Lorenzini ${ }^{6}$ \\ ${ }^{1}$ Department of Mechanical Engineering, MS Ramaiah Institute of Technology, Bengaluru 560001, India \\ ${ }^{2}$ Department of Industrial and Production Engineering, Malnad College of Engineering, Hassan 573 202, India \\ ${ }^{3}$ Department of Mechanical Engineering, Malnad College of Engineering, Hassan 573 202, India \\ ${ }^{4}$ Department of Mathematics, Government First Grade College for Women, Hassan 573 202, India \\ ${ }^{5}$ Department of Engineering and Architecture, University of Parma, Parco Area delle Scienze, Italy \\ ${ }^{6}$ Department of Industrial Engineering, Alma Mater Studiorum-University of Bologna, viale Risorgimento 2, Bologna 40136, \\ Italy
}

Corresponding Author Email: shashanklingappam@gmail.com

https://doi.org/10.18280/ijht.360425

Received: 10 March 2018

Accepted: 10 September 2018

\section{Keywords:}

alloy, microwaves, hybrid heating,

melting, casting, SEM

\begin{abstract}
Material deterioration caused during service life led to the development of erosive/corrosive resistant materials. The present work focuses on characterization of an alloy, naval brass, developed by microwave hybrid heating method, which is a vital material used in ship building/ marine industry. Mechanism of melting of metals by microwave hybrid heating technique is presented in the article. Microstructural study reveals formation of alpha and beta phases, with negligible porosity. X-Ray Diffraction study reveals the presence of CuZn phase in the developed alloy. Further, tensile and microhardness characteristics of the cast alloy holds good with the properties that must be exhibited by the specified standard material.
\end{abstract}

\section{INTRODUCTION}

Materials are designed for various types of applications and at the same time, materials must possess properties required for the specific application. Marine industries urge for materials that are erosion and corrosion resistant [1]. One such marine application that requires such materials is ship building. Materials used in ship building undergo erosion/ corrosion due to salinity [2]. Hence, materials must be capable of resisting the deterioration. Development of the materials for such application needs extensive research. Once the material is designed, it has to be developed/ manufactured. The developed material should possess the properties required for the applications.

Conventional method of material development is in existence for centuries. Metals are heated by the conventional means to produce molten liquids, further cast to desired size and shapes. Heat is transferred by the mode of conduction from the outside surface towards the centre of the material in conventional methods [3]. This may lead to several consequences like residual stress, porosity, non-uniform microstructure, etc. Bringing the material to thermal equilibrium requires more time and energy [4]. Further, temperature gradients result in unnecessary material losses during the process [5-6]. Major cause for these negative aspects of conventional processing is the way in which heat is transferred into the candidate material.

Melting process is observed to be responsible for consuming more than half of the energy costs in metal casting process. Energy efficiency of foundries depends largely on the process of melting. Even though energy consumption in melting process industries is of increased significance, industries have left with no option to go with the technology having lower energy efficiency. This technology should be replaced with a sustainable technology, which can deliver high quality products with lesser energy consumption. Further, the melting process also results in physical and chemical properties of the final product. It is noteworthy that the solubility of gases with molten metal increases with time and temperature, which results in undesirable defects like porosity [7]. The option available for reducing the solubility of gases is to achieve the process at least possible time, which may not be possible by conventional melting. Development of alloys requires higher temperature to melt the metals. All the stated disadvantages of conventional material processing can be eliminated by using a microwave material processing technique (MMP). MMP use electromagnetic radiation (microwaves) as a source of energy to develop heat in the material [8]. Heating of material takes place at the molecular level and is transferred from inside to the outer side [9-13]. However, MMP has some limitations, reflection of radiation when irradiated on metallic material at room temperature being the most important. Microwaves are reflected because of lower skin depth [14-19], that causes difficulty in processing of metals. However, microwaves are absorbed by the metallic materials at higher temperature [20]. To overcome the reflectivity of microwaves at room temperature and to process metallic material using microwaves, a new technique called Microwave Hybrid Heating (MHH) is employed [21]. MHH technique use microwave absorbing materials called susceptor to initially heat the candidate material through conventional mode. As the temperature reaches a certain point known as critical temperature $\left(\mathrm{T}_{\mathrm{c}}\right)$, metallic materials start absorbing microwaves, which leads to increase in skin depth 
[22]. Once microwaves are absorbed, metallic materials get heated uniformly at molecular level, irrespective of the material volume. Certain works have been reported regarding melting and casting of metallic materials through $\mathrm{MHH}$ [2328]. Further, it has been reported that microwave processing results in enhanced mechanical properties of the processed material [29-31]. Most of the conventional casting techniques affect the environment by releasing pollutants to the atmosphere. Therefore, the selected casting process must be able to take care of the factors affecting environment. In this regard, microwave processing acts an environmentally cleaner and greener process [32-33].

Present literature survey shows lot of scope for the research in development of an alloy by microwave casting method. Naval brass an alloy has been identified as one of the suitable material for the present work. An attempt has been made to develop through $\mathrm{MHH}$ and characterize the naval brass alloy.

\section{MATERIALS AND METHODS}

\subsection{Materials selection}

The main insight of the present work is to develop an alloy that has wide application. One such alloy made out of $59 \%$ copper, $40 \%$ zinc and $1 \%$ tin is naval brass, which finds broad applications in marine industry. Hence, naval brass is selected as an alloy to develop and to achieve the objective of the present work. Commercially available pure copper, zinc and tin are considered as initial alloying materials to develop naval brass. Copper is alloyed with zinc to obtain brass, while tin is added to overcome dezincification of brass in highly corrosive environments.

\subsection{Method}

A $3.3 \mathrm{~kW}$ microwave furnace, operating at $2.45 \mathrm{GHz}$ frequency is used in the present work. The furnace has a Ktype thermocouple to measure the temperature and is integrated with a controller to indicate and maintain the temperature. A schematic showing the system used in the present work is as shown in Fig. 1.

Prior to the development of an alloy, proper weighing of the alloying elements is necessary to obtain the required composition in the final product. Naval brass has copper and zinc as major alloying materials. Quantity of alloying elements is weighed (Make: Anamed Z-400 weighing balance). Description of certain particulars regarding the present work is tabulated in Table 1.

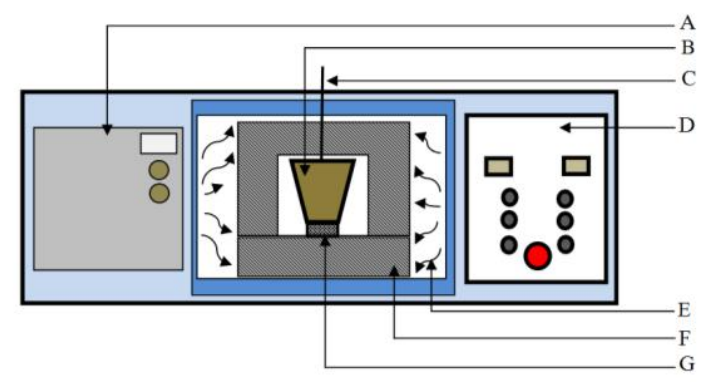

Figure 1. Schematic of microwave processing setup A - Chiller unit, B - Crucible, C - K-type Thermocouple D - Control panel, E- Microwaves, F - Insulation, $\mathrm{G}-$ Susceptor
Table 1. Description of particulars

\begin{tabular}{cc}
\hline Power & $3.3 \mathrm{~kW}$ \\
\hline Frequency & $2.45 \mathrm{GHz}$ \\
\hline Temperature measurement & K-type thermocouple \\
\hline Candidate materials & $\mathrm{Cu}, \mathrm{Zn}, \mathrm{Sn}$ \\
\hline Crucible & Graphite \\
\hline Susceptor & $\mathrm{SiC}$ \\
\hline Refractory shielding & Alumina \\
\hline
\end{tabular}

Initially, commercially available bulk copper is taken in a graphite crucible (B). The crucible is placed on a susceptor $(\mathrm{G})$ (SiC) block and enclosed with a microwave transparent refractory insulation $(\mathrm{F})$. The refractory insulation is further covered with glass wool to avoid dissipation of heat in to the furnace chamber during processing. A K-type thermocouple (C) is used to measure the temperature during the melting process. Trials were carried out to observe the time required for complete melting of copper (Melting temperature: $\mathrm{T}_{\mathrm{M}}=$ $\left.1083^{\circ} \mathrm{C}\right)$. Initial room temperature $\left(\mathrm{T}_{\mathrm{R}}\right)$ of the candidate material along with the temperature reading for every $5 \mathrm{~s}$ interval during the process is recorded. Figure 2 shows the time-temperature curve during microwave processing. The irradiated microwaves are reflected by copper at room temperature, owing to lower skin depth $(\sim 1.3 \mu \mathrm{m})$ [34]. Susceptor material placed below the crucible absorbs microwaves and generates heat energy. The developed heat energy is transferred to the candidate material by the mode of conduction. Once the candidate material reaches critical temperature, microwaves start to couple with the candidate material. This results in uniform volumetric heating of the candidate material until complete melting is achieved. Complete melting of copper is achieved in nearly 16 minutes. Once copper is melted, zinc is added in small quantities in the molten copper, followed by tin. The molten alloy is then poured in to a cavity made in the previously prepared sand mould and cooled in atmospheric air. Image of as-cast naval brass and the tensile specimens are shown in Fig. 3a and 3b respectively.

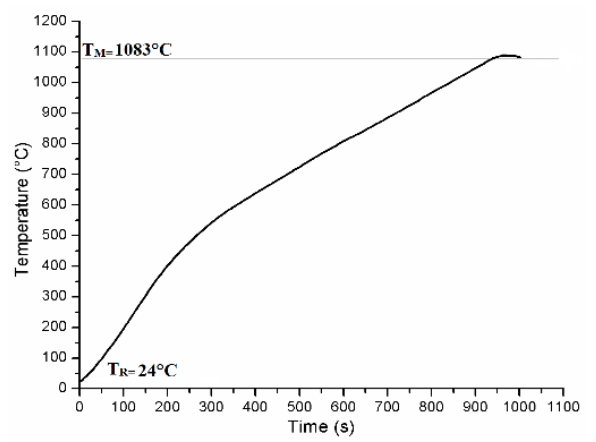

Figure 2. Variation of temperature with time during microwave casting

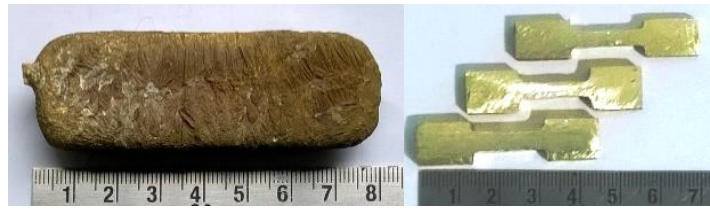

(a)

(b)

Figure 3. (a) As-cast brass developed by microwave casting (b) Tensile specimens prepared from as-cast naval brass 


\subsection{Characterization}

The developed naval brass is characterized for microstructural and mechanical properties. The developed alloy was sectioned by using a low speed diamond cutter (Make: Chennai Metco, India; Model: Baincut - LSS) and cleansed with acetone prior to characterization. Specimens were polished using different grades of emery papers. Further, the specimens were polished using diamond paste to get mirror finished surface followed by etching. A chemical reagent prepared by mixing equal parts of nitric acid and distilled water is used as an etchant for the developed naval brass. Metallographic specimens were etched by immersing in the prepared reagent with $5 \mathrm{~s}$ holding time.

X-Ray Diffraction (XRD) was carried out using PANalytical $\mathrm{X}$ Pert $^{3}$ Powder Diffractometer by directing the $\mathrm{Cu} \mathrm{K} \alpha \mathrm{X}$-Rays onto the brass between the angles $10^{\circ}$ to $90^{\circ}$ at a rate of $1^{\circ} \%$ min. TESCAN VEGA 3 Scanning Electron Microscope (SEM) attached with Energy Dispersive X-Ray Spectroscopy (EDS) is used to study the microstructure and to carry out elemental studies. Mechanical characterization like tensile test and microhardness study has also been carried out. Dimensions of the brass tensile specimens were made as per ASTM E8/ E8 M-09 standards (Fig. 4). Tensile test was conducted at room temperature using Mecmesin 10-i Universal Testing Machine (UTM) at a strain rate of $0.015 \mathrm{~mm} / \mathrm{min}$. Microhardness of the as-cast brass developed is measured using Highwood Vickers' Microhardness Tester HWMMT - X7.

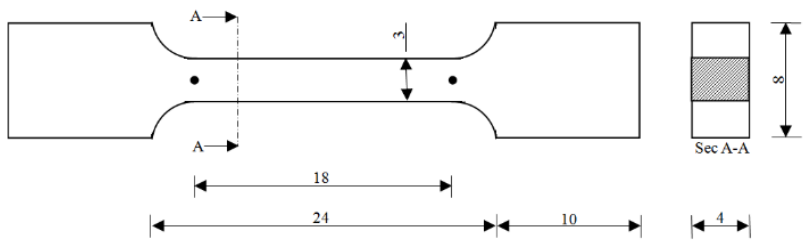

Figure 4. Schematic showing dimensions of the ASTM E8/ M-09 tensile specimen [35]

\section{MECHANISM OF MELTING BY MICROWAVE HYBRID HEATING}

Physics involved during the interaction of microwaves with metallic materials is still not completely established. However, few theoretical aspects are acceptable. This section describes the behaviour of microwaves with metals. A representation is shown in Fig. 5 for explaining the interaction of metals during microwave irradiation.

Metals are good conductors of heat and electricity and good conductors are known to have lower skin depth $(\delta)$. Skin depth is defined as the depth of penetration of electromagnetic radiations from the surface of the material at which the density falls to (1/e) of its value [36]. Attributing to the lower skin depth, microwaves are reflected at room temperature when irradiated on the metallic materials as shown in Fig. 5a. Reflection is caused by the free moving electrons that induces magnetic field in the direction opposite to that of the irradiated electromagnetic waves [20].

With the increase in temperature, the intensity of induced magnetic field attenuates and the depth of penetration of electromagnetic radiation increases. As the temperature raises upto a certain elevated level, depth of penetration of microwaves into the metal becomes sufficient for the absorption and the corresponding temperature is known as 'Critical Temperature $\left(\mathrm{T}_{\mathrm{C}}\right)$ '. In order to reach the critical temperature, heat energy must be supplied to the candidate material from an alternate source. Such material which supplies heat energy is called as 'Susceptor', which is capable of absorbing microwaves and converting it to heat energy. Heat energy generated by the susceptor is transferred to the candidate material as shown in Fig. 5b. As the temperature reaches the critical temperature, candidate material begins to absorb microwaves directly, there by resulting in molecular level heating (Fig. 5c). The candidate material undergoes twoway heating from this point onwards until complete melting is achieved; first is conduction by the susceptor and second is direct heating by microwaves. Direct heating is caused as a result of friction between moving charges that takes place due to the varying electro-magnetic (EM) irradiation (Fig. 5d). This method of heating metals is popularly known as Microwave Hybrid Heating (MHH).

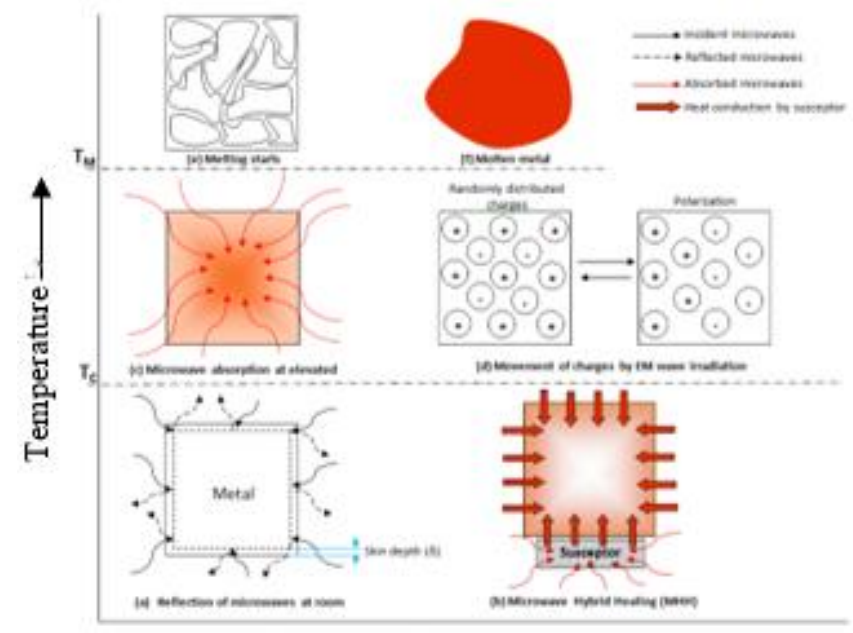

Figure 5. Behaviour of metals during microwave interaction

\section{RESULTS AND DISCUSSIONS}

Melting of highly conductive materials by microwave energy is a difficult process. However, in the present work, bulk metals like copper, zinc and tin are melted by microwave hybrid heating and blended to develop an alloy. Results obtained by characterization of the developed as-cast alloy are discussed below.

\subsection{XRD study}

A typical spectrum of XRD of the developed microwave melted as-cast naval brass is shown in Fig. 6. Five major peaks are indicated in the XRD spectrum. Melting was carried out in the atmospheric conditions; consequently copper oxide formation was also detected in the diffraction pattern. This could be due to the inevitability of oxide formation during interaction of the candidate material with atmospheric oxygen at high temperatures, which is evident from EDS mapping (Fig. 8). The peak associated with $2 \theta \approx 42^{\circ}$ indicates partial transformation of copper into copper oxide during the process and subsequent formation of brass on addition of zinc. However, the intensity of oxide presence is not found to be very significant in the XRD analysis. Hence, phases like $\mathrm{Cu}_{3} \mathrm{Zn}_{2}$ and $\mathrm{CuZn}$ have been dominantly formed during 
microwave processing, which is evident from the elemental analysis carried out by EDS (Fig. 8). Presence of oxides during microwave processing further helps in faster rate of material heating during microwave processing [37]. Major peak of brass $\left(\mathrm{Cu}_{3} \mathrm{Zn}_{2}\right)$ corresponds to the position $2 \theta$ value of $42.52^{\circ}$ (1 110 ). Further, $\mathrm{CuZn}$ phase is identified at various other peaks corresponding to $2 \theta$ values $\approx 44^{\circ}\left(\begin{array}{lll}1 & 1 & 0\end{array}\right), 50^{\circ}\left(\begin{array}{lll}2 & 0 & 0\end{array}\right), 73^{\circ}(22$ $0), 88^{\circ}\left(\begin{array}{lll}3 & 1 & 1\end{array}\right)$.

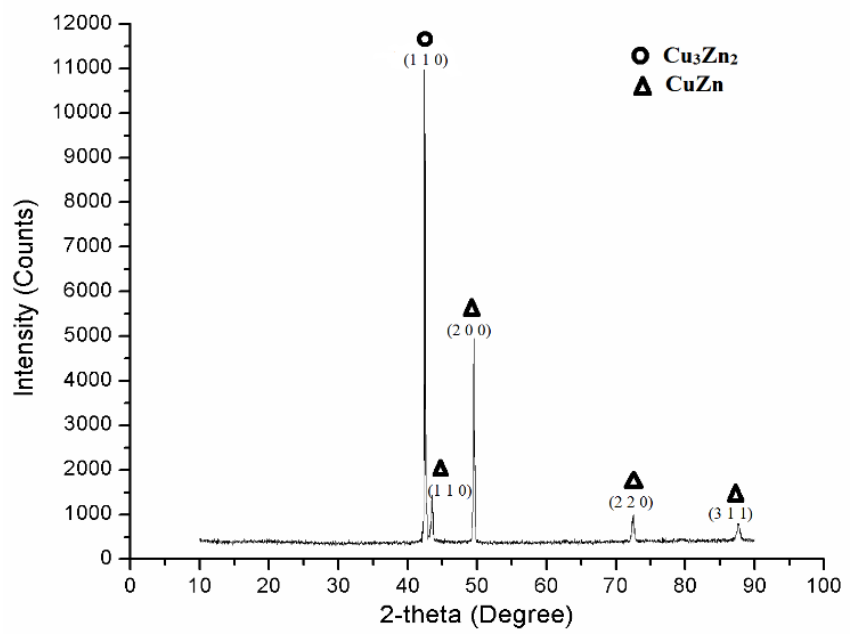

Figure 6. XRD spectrum of the developed as-cast naval brass

\subsection{Microstructural and elemental analysis}

Microstructural investigation of naval brass developed by microwave casting is carried out and the scanning electron micrographs of developed as-cast brass are shown in Fig. 7. Schematic of the as-cast naval brass along with the crosssectional view of the area selected for microstructural study is shown in Fig. 7a. Morphological investigation shows the alpha-beta dual-phase of brass. During solidification, alpha phase can be seen dispersed into the beta matrix (Fig. 7b). Beta phase matrix enhances hardness of the alloy which has a BCC structure. Elongated structure can be seen at the periphery, while equiaxed structure formation at the centre of the cast brass (Fig. 7c \& 7d). This is due to faster rate of cooling at the outer side of the cast while slow cooling at the core takes place due to the latent heat.

Elemental studies of the as - cast brass is carried out using Quorum Software integrated with TESCAN VEGA 3 Scanning Electron Microscope, and a typical EDS spectrum obtained for area mapping of the microstructure is shown in Fig. 8. Further, oxide also shows its presence due to the interaction of brass with atmosphere, which could be correlated with the presence of oxide phase observed during XRD analysis. Distribution of elements was observed by elemental mapping, which shows dominant copper phase along with significant presence of zinc in the as - cast brass, along with tin distributed uniformly (Fig. 9). Addition of tin avoids dezincification, which is one of the major problems of brass in corrosive environment.

To verify the composition of the developed alloy, Optical Emission Spectroscopy (OES) was carried out using BAIRD - DV 6E spectrometer. Chemical composition of the developed as-cast brass is presented in Table 2, which falls good with the elemental study made by EDS (Fig. 8) on the developed alloy.
Table 2. Chemical composition of as-cast brass

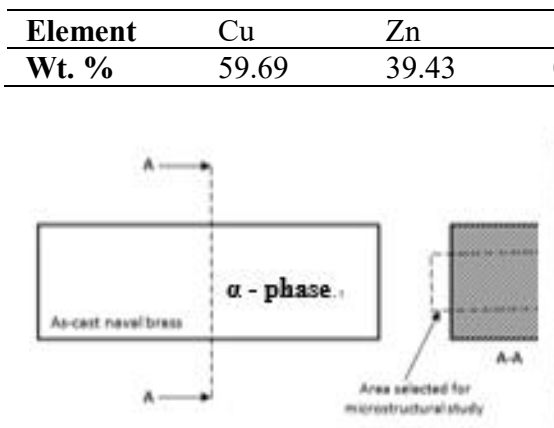

(a)

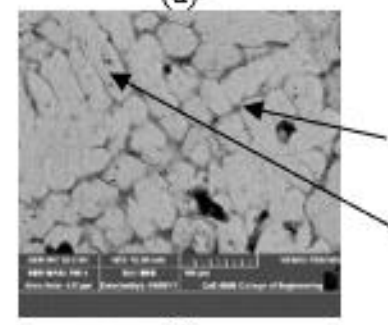

(c)

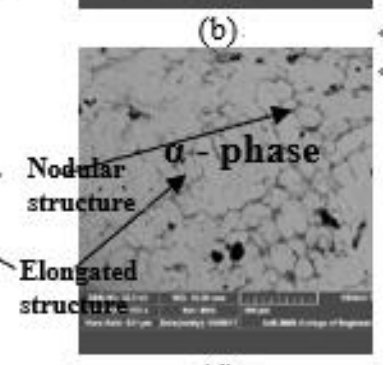

(d)
Figure 7. Cross-section view of the area selected for microstructural study of as-cast naval brass and SEM images of naval brass developed by microwave casting

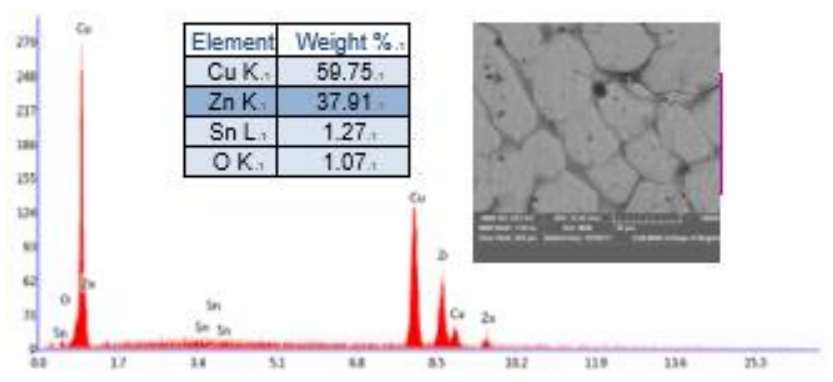

Figure 8. EDS spectrum of as-cast naval brass

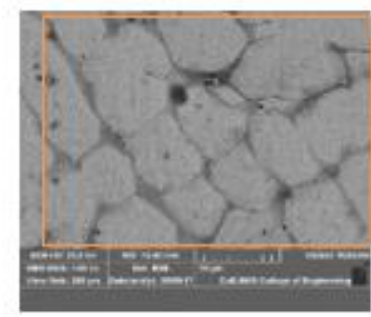

(a)

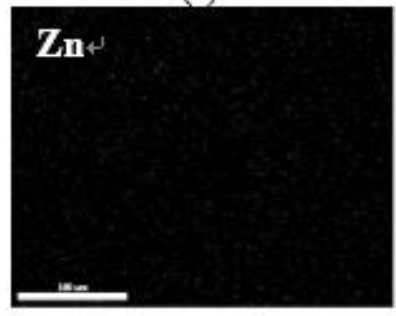

(c)

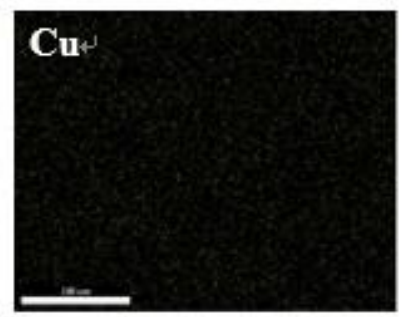

(b)

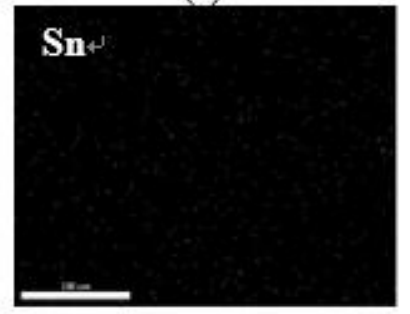

(d)
Figure 9. Map showing distribution of elements in as-cast brass (a) Area selected for elemental mapping (b) Region showing distribution of copper $(\mathrm{Cu})(\mathrm{c})$ Region showing distribution of zinc ( $\mathrm{Zn}$ ) (d) Region showing distribution of tin $(\mathrm{Sn})$ 


\subsection{Tensile test}

Tensile properties of the microwave hybrid heated as-cast naval brass was evaluated as indicated in the earlier section. Tensile test was carried out on three test specimens and their average value is considered. Tensile properties like ultimate tensile strength, yield strength and percentage elongation are recorded and presented. Figure 10 shows strain - stress curve for microwave cast naval brass. It is observed from the figure that upto the initial loading of around $185.14 \mathrm{MPa}$ (Yield strength), the test specimen exhibits elastic characteristics. Further, increase in the tensile loading leads the material to plastically deform till it reaches its ultimate tensile strength of 347.24 MPa. Additional loading of the test specimen after ultimate stress results in fracture. The candidate material no longer withstands any tensile load, beyond which stress value drops drastically. Ductility of the test specimen is measured by elongation of the specimen due to tensile loading. Nearly $28.87 \%$ elongation was observed on the test specimen, which features significantly good ductility. Moreover, additional elongation is limited due to the increased presence of zinc in the as-cast brass, as observed from the EDS spectrum (Fig. 7). The observed strength could be due to uniform distribution of phases caused by heating of material at molecular level by microwave energy.

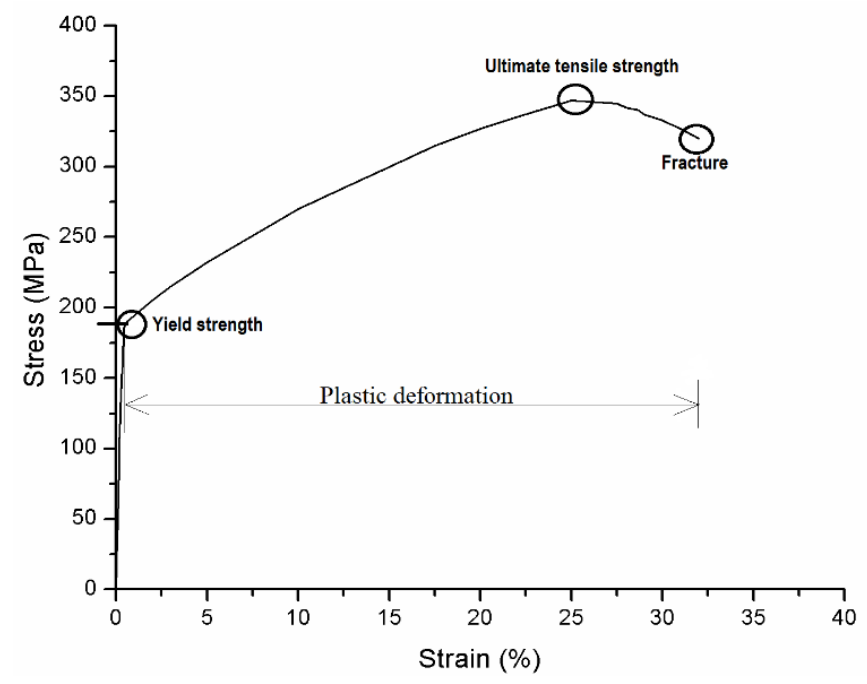

Figure 10. Stress - Strain behaviour of as-cast naval brass

Fractography on the fractured tensile specimens has been carried out and the fractographs are presented in Fig. 11. Close observation on the fractured surface shows fine dimples, which is evident of the better ductile property of the developed alloy [38]. Further, voids can also be seen in the microstructure, which characterizes the initiation of dimples. Cleavage formation is also noticed in the Fig. $11 \mathrm{~b} \& \mathrm{c}$, which characterizes the area of fracture of the tensile specimen. Fractograph shows multimode fracture with dimples, cleavage and facets. Cleavage formation indicates that the developed ascast naval brass has significant hardness, which could be due to the presence of beta phase. In addition, further elongation of the as-cast naval brass is restricted by formation of cleavage and undergoes fracture. Moreover, the developed as-cast brass shows negligible porosity as observed from the micrographs (Fig. 6) and fractographs (Fig. 11), resulting in lower rate of crack propagation and thus resulting in better strength of the material.

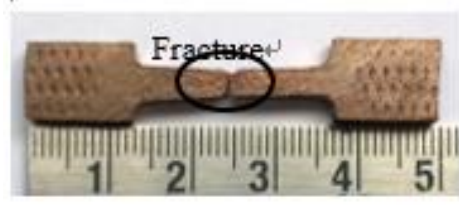

(a)

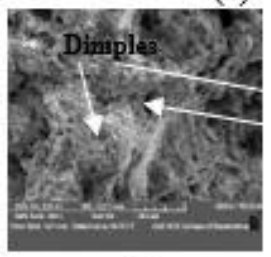

(c)

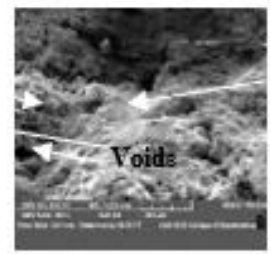

(d)

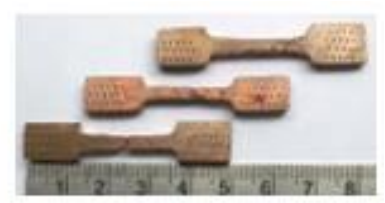

(b)

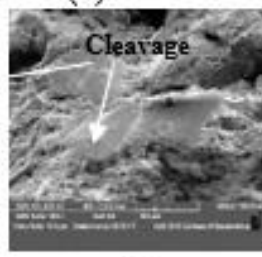

(e)
Figure 11. (a) Fracture region (b) Fractured Tensile specimens Fractography images showing (c) dimples (d) voids (e) cleavage

\subsection{Microhardness study}

One of the important factors that influence the performance of a material is its hardness. Increased hardness results in increase in resistance of a material to wear and corrosion. Indentations were made at five different locations randomly on the transverse section of the developed as-cast brass, starting from top to the bottom of the cast alloy. Distribution of the microhardness and the indentations made on the as-cast alloy is presented in Fig. 12.

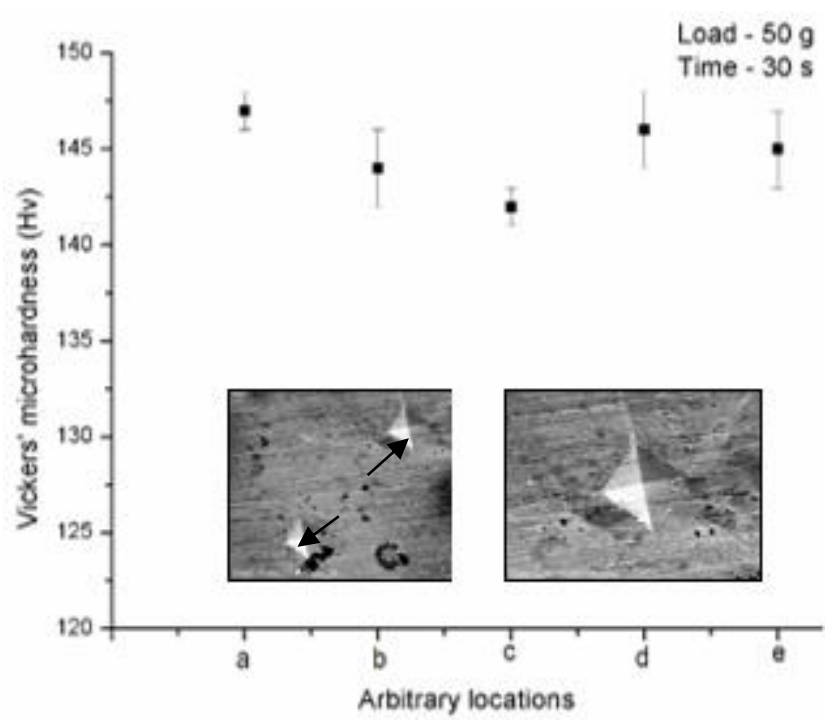

Figure 12. Vicker's microhardness distribution and indentations

Average microhardness of the developed as-cast brass is measured to be $145 \pm 3 \mathrm{Hv}$. Microhardness distribution is observed to be nearly consistent, which could be due to uniform distribution of metals to form an alloy / uniform dispersion of alpha phase in the beta phases. Indentations made on the developed alloy are observed to be significantly well defined, which attributes to the better hardness of the developed alloy owing to the presence of beta phase. Formation of $\alpha$ and $\beta$ phases is due to the presence of more than $37.5 \%$ zinc in the developed as-cast brass. Further, it is evident that the formation of fine dimples observed from the fractographs (Fig. 11c) that as-cast naval brass exhibits better hardness. 


\section{CONCLUSIONS}

In spite of the difficulties in processing metallic materials by microwaves, copper is melted by microwave hybrid heating. Further, naval brass is developed by adding alloying elements like zinc and tin to the molten copper. Developed as-cast naval brass is characterized and the following conclusions are drawn from the present work.

(1) Naval brass, an alloy of copper is developed by using microwave hybrid heating.

(2) Time required for developing the alloy by microwave casting technique is recorded to be 17 minutes.

(3) XRD study reveals the dominant presence of $\mathrm{Cu}_{3} \mathrm{Zn}_{2}$ and $\mathrm{CuZn}$ phases. Oxide also shows its presence with very negligible intensity, which could be attributed to carrying out experimentation in atmospheric conditions.

(4) Uniform and better distribution of alloying elements is observed from the elemental mapping study.

(5) SEM observations reveal elongated structure at the periphery and nodular microstructure at the core of the as-cast alloy.

(6) Average ultimate tensile strength of the developed ascast naval brass/ alloy is found to be $347.24 \mathrm{MPa}$.

(7) Microhardness study shows the hardness of the developed as-cast alloy has been found to be distributed equally throughout, and is found to be $145 \pm 3 \mathrm{Hv}$.

\section{ACKNOWLEDGEMENT}

Authors would like to acknowledge All India Council for Technical Education for providing financial support for the present work [Ref. No.: 01/RIFD/RPS/POLICY-1/2014-15].

\section{REFERENCES}

[1] Ashkenazi D, Cvikel D, Stern A, Kahanov Y. (2014). Metallurgical characterization of brass objects from the Akko 1 shipwreck, Israel. Mater Charac 92: 49-63. http://dx.doi.org/10.1016/j.matchar.2014.02.012

[2] Yamamoto N, Ikegami K. (1998). A study on the degradation of coating and corrosion of ship's hull based on the probabilistic approach. J Offshore Mechanics and $\begin{array}{lll}\text { Arctic } & \text { Engg. } & 120(3) \text { : }\end{array}$ https://doi.org/10.1115/1.2829532

[3] Ripley EB, Oberhaus JA. (2005). Melting and heat treating metals using microwave heating. Ind Heat 72: 61.

[4] Ji CX, Cui Y, Zeng Z, Tian ZH, Zhao CL, Zhu GS. (2005). Continuous casting of high-al steel in Shougang Jingtang steel works. J Iron and Steel Res 22: 53-56. https://doi.org/10.1016/S1006-706X(15)30138-2

[5] Moore AF, Donald ES, Marvin SM. (2006). Method and apparatus for melting of metals. U.S. Patent No. 7,011,136.

[6] Warren B, Awida MH, Fathy AE. (2012). Microwave heating of metals. IET Microwaves, Antennas \& Propagation 6(2): 196-205. http://dx.doi.org/10.1049/ietmap.2010.0494

[7] U. S. Department of Energy. (2015). Advanced melting technologies: Energy saving concepts and opportunities. BCS Incorporated, Columbia.

[8] Agrawal D. (2012). Latest global developments in microwave materials processing. Mater Res Innov 14(1):
3-8.

https://doi.org/10.1179/143307510X12599329342926

[9] Osepchuk JM. (1984). A history of microwave heating applications. IEEE Transactions on Microwave Theory and Techniques 32(9): 1200-1224. http://dx.doi.org/10.1109/TMTT.1984.1132831

[10] Sutton WH. (1989). Microwave processing of ceramic materials. American Cer Soc Bull 68(2): 376-386.

[11] Thostenson ET, Chou TW. (1989). Microwave processing: Fundamentals and applications. Compos Part A 30: 1055-1071. http://dx.doi.org/10.1016/S1359835X(99)00020-2

[12] Clark DE, Sutton WH, Lewis D. (1996). Microwave processing of materials. Ann Rev Mater Sci 26: 299-301. http://dx.doi.org/10.1146/annurev.ms.26.080196.00150 3

[13] Sharma AK, Aravindan S, Krishnamurthy R. (2001). Microwave glazing of alumina-titania ceramic composite coatings. Mater Let 50: 295-301. http://dx.doi.org/10.1016/S0167-577X(01)00243-9

[14] Roy R, Agrawal D, Cheng J, Gedevanishvili S. (1999). Full sintering of powdered metal parts in microwaves. Nature 399: 668-670. https://doi.org/10.1038/21390

[15] Chillar P, Agrawal D, Adair JH. (2008). Sintering of molybdenum metal powder using microwaves energy. Powder Metall 51(2): 182-187. https://doi.org/10.1179/174329007X178001

[16] Mondal A, Agrawal D, Upadhyaya A. (2009). Microwave heating of pure copper powder with varying particle size and porosity. J Microwave Power and Electromagnetic Energy 43(1): 5-10. https://doi.org/10.1080/08327823.2008.11688599

[17] Rodiger K, Dreyer K, Gerdes T, Willert PM. (1998). Microwave Sintering of Hardmetals. Inter J Refrac Met Hard Mater 16: 409-416. https://doi.org/10.1016/S02634368(98)00050-X

[18] Edwin BD. (2008). Microwave brazing process. US Patent No. 7775416B2.

[19] Sharma AK, Srinath MS, Kumar P. (2009). Microwave joining of metallic materials. Indian Patent Application no. 1994/Del/2009.

[20] Mishra RR. Sharma AK. (2016). Microwave-material interaction phenomena: Heating mechanisms, challenges and opportunities in material processing. Compos Part A 81: 78-97. https://doi.org/10.1016/j.compositesa.2015.10.035

[21] Bhattacharya M, Basak T. (2016). A review on the susceptor assisted microwave processing of materials. Energy 97: 306-338. https://doi.org/10.1016/j.energy.2015.11.034

[22] Gupta D, Sharma AK. (2011). Investigation WC10Co2Ni on sliding wear performance of cladding developed through microwave irradiation. Wear 271(910): https://doi.org/10.1016/j.wear.2010.12.037 $1642-1650$.

[23] Chandrasekaran S, Basak T, Ramanatahan S. (2011). Experimental and theoretical investigation on microwave melting of metals. J Mater Process Tech 211(3): 482-487 https://doi.org/10.1016/j.jmatprotec.2010.11.001

[24] Shashank L, Srinath MS, Amarendra HJ. (2017). Microstructural and mechanical investigation of aluminium alloy (Al 1050) melted by microwave hybrid heating. Mater Res Exp 4. https://doi.org/10.1088/20531591/aa7aaf 
[25] Mishra RR, Sharma AK. (2016). On mechanism of insitu microwave casting of aluminium alloy 7039 and cast microstructure. Mater Des 112: 97-106. https://doi.org/10.1016/j.matdes.2016.09.041

[26] Shashank L, Srinath MS, Amarendra HJ. (2017). Microstructural investigation and characterization of bulk brass melted by conventional and microwave processing methods. Mater Sci Forum 890: 356-361 2017.

https://doi.org/10.4028/www.scientific.net/MSF.890.35 6

[27] Shashank L, Srinath MS, Amarendra HJ. (2017). Melting of $60 \mathrm{Sn} 40 \mathrm{~Pb}$ alloy using microwave energy and its characterization. Mater Today: Proc 4(2): 471-476. https://doi.org/10.1016/j.matpr.2017.01.047

[28] Singh S, Gupta D, Jain V. (2016). Novel microwave composite casting process: Theory, feasibility and characterization. Mater Des 111: 51-59. https://doi.org/10.1016/j.matdes.2016.08.071

[29] Badiger R, Narendranath S, Srinath MS. (2015). Joining of Inconel-625 alloy through microwave hybrid heating and its characterization. J Manuf Process 18: 117-123. https://doi.org/10.1016/j.jmapro.2015.02.002

[30] Leonelli C, Veronesi P, Denti L., Gatto A., Iuliano L. (2008). Microwave assisted sintering of green metal parts. J Mater Process Tech 205(1-3): 489-496. https://doi.org/10.1016/j.jmatprotec.2007.11.263

[31] Saitou K. (2006). Microwave sintering of iron, cobalt, nickel, copper and stainless steel powders. Scripta Mater
$54:$ $875-879$

https://doi.org/10.1016/j.scriptamat.2005.11.006

[32] Calle I, Rodriguez MC. (2017). Microwaves for greener extraction. The Application of Green Solvents in Separation Processes, pp. 253-300.

[33] Metaxas AC, Meredith R. J. (1983). Industrial microwave heating. Ed. 4, IET, London, UK.

[34] Srinath MS, Sharma AK, Kumar P. (2011). A new approach to joining of bulk copper using microwave energy. Mater Des 32: 2685-2694. https://doi.org/10.1016/j.matdes.2011.01.023

[35] ASTM Designations: E8/M-09. (2009). Standard test methods for tension testing of metallic materials. American association state highway and transportation officials standard AASHTO No. T68, An American National Standard, 2009:1-3.

[36] Gupta M, Leong EWW, Wong WL. (2007). Microwaves and metals. John Wiley and Sons, Singapore.

[37] Takayam S, Saito Y, Sato M, Nagasaka T, Muroga T, Ninomiya Y. (2006). Sintering behavior of metal powders involving microwave-enhanced chemical reaction. Japan J App Phy. 45(1): 1816-1822. https://doi.org/10.1143/JJAP.45.1816

[38] Heidarzadeh, Saeid TA. (2016). A comparative study of microstructure and mechanical properties between friction stir welded single and double phase brass alloys. Mater Sci Engg: A 649: 349-358. https://doi.org/10.1016/j.msea.2015.10.012 